\title{
O “AMOR À PÁTRIA": REPRESENTAÇÕES DE CIVISMO NAS PÁGINAS DO DESPERTAR
}

\author{
Elisangela Cândido da Silva Dewes \\ Universidade de Caxias do Sul \\ eliscsd22@gmail.com
}

José Edimar de Souza Universidade de Caxias do Sul jesouza1@ucs.br

\section{RESUMO}

Este artigo é um fragmento de estudo desenvolvido em torno do Jornal Despertar, um impresso pedagógico produzido pela Diretoria de Instrução Pública do município gaúcho de Caxias do Sul, entre 1947 e 1954. O estudo buscou analisar as estratégias utilizadas, por meio da publicação do Despertar, para a disseminação de representações de civismo entre as comunidades das escolas rurais caxienses, e verificar as expectativas da administração pública municipal sobre as contribuições dessas ideias para as práticas dos habitantes das regiões rurais. Como aporte teórico foram utilizados conceitos da História Cultural e como metodologia análise documental de cinquenta e três edições do periódico. A investigação resultou no entendimento de que administração municipal valeu-se do periódico como um meio para fortalecer as representações sobre um arquétipo de "cidadão brasileiro" e, dessa forma, influenciar a comunidade rural aos comportamentos de civismo.

Palavras-chave: Civismo. Educação Rural. Imprensa educacional.

\section{EL "AMOR DE LA PATRIA": REPRESENTACIONES DEL CIVISMO EN LAS PÁGINAS DEL DESPERTAR RESUMEN}

Este artículo es un fragmento de un estudio desarrollado en torno al Jornal Despertar, forma pedagógica elaborada por la Junta de Instrucción Pública de la ciudad de Caxias do Sul, entre 1947 y 1954. El estudio buscó analizar las estrategias utilizadas, a través de la publicación de Despertar, para la difusión de las representaciones cívicas entre las comunidades de escuelas rurales de Caxienses, y verificar las expectativas de la administración pública municipal sobre los aportes de estas ideas a las prácticas de los habitantes de las regiones rurales. Como aporte teórico se utilizaron conceptos de Historia Cultural y como metodología de análisis documental de cincuenta y tres ediciones de la revista. La investigación resultó en el entendimiento de que la administración municipal utilizó el periódico como un medio para fortalecer las representaciones sobre un arquetipo de "ciudadano brasileño" y, de esta manera, incidir en la comunidad rural hacia el comportamiento cívico.

Palabras clave: Civismo. Educación Rural. Prensa Educativa.

\section{THE "LOVE OF THE HOMELAND": REPRESENTATIONS OF CIVISM ON THE DESPERTAR}




\section{ABSTRACT}

This article is a fragment of a study developed around the Jornal Despertar, a pedagogical form produced by the Board of Public Instruction of the city of Caxias do Sul, between 1947 and 1954. The study sought to analyze the strategies used, through the publication of Despertar, for the dissemination of civic representations among the communities of rural schools in Caxienses, and to verify the expectations of the municipal public administration on the contributions of these ideas to the practices of the inhabitants of the regions rural. As a theoretical contribution, concepts from Cultural History were used and as a methodology document analysis of fiftythree editions of the journal. The investigation resulted in the understanding that municipal administration used the periodical as a means to strengthen representations about an archetype of "Brazilian citizen" and, in this way, to influence the rural community to civic behavior.

Keywords: Civism. Rural Education. Educational Press.

\section{L '«AMOUR DE LA TERRE»: REPRÉSENTATIONS DU CIVISME SUR LES PAGES DE DESPERTAR}

\section{RÉSUMÉ}

Cet article est un fragment d'une étude développée autour du Jornal Despertar, une forme pédagogique produite par le Conseil d'Instruction Publique de la ville de Caxias do Sul, entre 1947 et 1954. L'étude a cherché à analyser les stratégies utilisées, à travers la publication de Despertar, pour la diffusion des représentations civiques parmi les communautés d'écoles rurales de Caxienses, et à vérifier les attentes de l'administration publique municipale sur les apports de ces idées aux pratiques des habitants des régions rurales. Comme contribution théorique, des concepts de l'histoire culturelle ont été utilisés et comme une analyse documentaire de la méthodologie de 53 éditions de la revue. L'enquête a abouti à la compréhension que l'administration municipale a utilisé le périodique comme un moyen de renforcer les représentations sur un archétype de «citoyen brésilien» et, de cette manière, d'influencer la communauté rurale à un comportement civique.

Mots-clés: Civisme. Éducation Rurale. Presse Éducative.

\section{INTRODUÇÃO}

A história se ocupa de fenômenos que ocorrem em determinado espaço e tempo. Ao recortar e organizar fatos do tempo e do espaço constrói infinitas possibilidades para sua compreensão. Ao empregar uma teoria e desenvolver uma metodologia produz e atribui sentido ao passado. Esta pesquisa na área da História da Educação utiliza como objeto de estudo um aparato de imprensa educacional que teve circulação na cidade gaúcha de Caxias do Sul, intitulado de Despertar. Essa produção foi coordenada pela Diretoria de Instrução Pública de 
Caxias do Sul, e tinha como público-alvo os professores, os alunos e a comunidade que vivia no entorno das escolas rurais.

O estudo buscou analisar as estratégias utilizadas, por meio da publicação do Despertar, para a disseminação de representações de civismo entre as comunidades das escolas rurais caxienses, e verificar as expectativas da administração pública municipal sobre as contribuições dessas ideias para as práticas dos habitantes das regiões rurais, considerando-se o período de 1947 a 1954, anos de circulação do Despertar.

Como aportes o estudo utilizou teóricos e outras pesquisas no campo da História Cultural, evoluindo para conceitos tais como o de representações, apropriação e de práticas. Para Souza (2012) a opção pela abordagem da História Cultural, considera aspectos de contexto e evidencia os sentidos construídos pelos sujeitos em um determinado espaço e tempo. Desse modo, a abordagem histórica compreende e mobiliza conceitos a partir da cultura como "[...] um conjunto de significados partilhados e construídos pelos homens para explicar o mundo" (PESAVENTO, 2006, p. 49). Os conceitos de Chartier (1988) sobre as representações cooperaram para a análise do objeto dessa pesquisa, pois tratam sobre a concepção de sentidos a partir dos vários tipos de leitores, que são modelados pelas práticas promovidas pelos distintos grupos sociais, em diferentes momentos da história:

[...] As estruturas do mundo social não são um dado objetivo, tal como o não são as categorias intelectuais e psicológicas: todas elas são historicamente produzidas pelas práticas articuladas (políticas, sociais, discursivas) que constroem as suas figuras. São estas demarcações, e os esquemas que as modelam, que constituem o objeto de uma história cultural levada a repensar completamente a relação tradicionalmente postulada entre o social, identificado com um real bem real, existindo por si próprio, e as representações, supostas como refletindo-o ou dele se desviando. Por outro lado, esta história deve ser entendida como o estudo dos processes com os quais se constrói um sentido. Rompendo com a antiga ideia que dotava os textos e as obras de um sentido intrínseco, absoluto, único - o qual a crítica tinha a obrigação de identificar -, dirige-se as práticas que, pluralmente, contraditoriamente, dão significado ao mundo. (CHARTIER, 1988, p. 27).

Esse caminho teórico possibilitou reconhecer aspectos do recorte temporal analisado, no contexto rural, evidenciando as representações disseminadas e construídas a partir da imprensa pedagógica. Ainda, segundo Chartier (1988), os textos mostram perspectivas semânticas que atuam sobre a experiência, produzindo representações que podem ser reconhecidas e postas em prática. Essas concepções possibilitaram admitir que a observação sobre as edições do periódico, precisariam ser confrontadas com outros documentos que pudessem confirmar ou contrapor as hipóteses levantadas durante a pesquisa. 
Desse modo, a metodologia utilizada para a investigação considerou a análise documental, que aconteceu sobre 53 edições do Despertar, e abrangeu a investigação de diferentes elementos que compunham cada edição do periódico. Corroborou para a compreensão do conteúdo do Despertar, a análise de outras fontes documentais, que foram localizadas nos acervos históricos locais; ainda compôs o acervo documental do estudo a transcrição da entrevista realizada por historiadores da cidade de Caxias do Sul, com a professora Ester Troian Benvenutti, que foi coordenadora do periódico e responsável pelo órgão municipal de ensino caxiense.

Nesse contexto, a análise documental fez emergir evidências que cooperaram para o entendimento sobre as práticas das comunidades das áreas rurais, e também sobre o modo como as representações povoaram essas localidades, influenciando as pessoas que ali viviam ao exercício de determinadas práticas. Chartier (1991) relaciona a apropriação à leitura dos textos, considera que a recepção e a interpretação dada por cada indivíduo, tem lugar nos sentidos que foram construídos e que foram validados a partir das práticas desenvolvidas dentro de diferentes grupos, por isso para o historiador existe uma pluralidade de leituras, o que influencia na percepção do leitor:

[...] a apropriação visa uma história social dos usos e das interpretações, referidas a suas determinações fundamentais e inscritas nas práticas específicas que as produzem. Assim, voltar a atenção para as condições e os processos que, muito concretamente, sustentam as operações de produção do sentido (na relação de leitura, mas em tantos outros também) é reconhecer, contra a antiga história intelectual, que nem as inteligências nem as ideias são desencarnadas, e, contra os pensamentos do universal, que as categorias dadas como invariantes, sejam elas filosóficas ou fenomenológicas, devem ser construídas na descontinuidade das trajetórias históricas. (CHARTIER, 1991, p.180).

Para este estudo, considerou-se que o Despertar foi um aparato utilizado pela administração pública municipal para a propagação de representações que influenciaram a comunidade da área rural de Caxias do Sul a adotarem determinadas práticas, de modo especial, as que estavam relacionadas as manifestações de civismo.

\section{REPRESENTAÇÕES DE CIVISMO NAS PÁGINAS DO DESPERTAR}


O amor pela pátria Brasil e a exaltação aos seus símbolos foram temas que apareceram nas páginas do Despertar ${ }^{1}$. Apesar da aparente simpatia dos editores do periódico ${ }^{2}$ pelos assuntos categorizados neste trabalho como civismo, não havia uma coluna fixa no periódico que tratasse exclusivamente sobre o assunto. O civismo apareceu em distintos espaços, contabilizando um total de 272 registros - de um total de 1840 itens analisados. Notadamente, parte desses registros apareciam em formato de texto prescritivo, onde se acredita haver uma tentativa de disseminar conhecimentos que cooperassem para ajustar o comportamento das pessoas que viviam nas áreas rurais, moldando-os conforme o que se imaginava ser o ideal de "cidadão brasileiro". As matérias com teor prescritivo abordavam sobre comportamentos que representavam o amor à pátria, e que eram enquadrados como “obrigações” à nação. Prescrições como as do trecho a seguir: “[...] Considera a bandeira como imagem viva da Pátria, prestandolhe o culto do teu amor e servindo-a com todas as forças do teu coração. Honra a Pátria no Passado: sôbre os túmulos dos heróis; glorifica-a no presente: com a virtude e o trabalho [...]" (DESPERTAR, 1951a, p. 4). A exaltação aos símbolos pátrios ainda foi observada em trechos, tais como: "A bandeira é a Pátria, quando se desdobra agitada soberba, augusta eletrizante [...]" (DESPERTAR, 1948c, p. 1).

De acordo com Tambara e Arriada (2009), em meados do século XX, houve uma campanha que tratou de disseminar valores que estavam associados ao civismo e ao moralismo patriótico. Partindo do esforço de intelectuais brasileiros na propagação de uma ideologia que tinha premissas republicanas, nomes como o de Olavo Bilac, Coelho Neto, Medeiros de Albuquerque e João Simões Lopes Neto, figuram entre esses intelectuais.

Outros recortes históricos mostram semelhante entusiasmo na propagação de um pensamento cívico, tal como o do governo Vargas, onde observou-se o fortalecimento de políticas para a consolidação de um modelo de cidadão brasileiro, inspirado pelo nacionalismo. De acordo com Aguiar Junior (2013), nos anos de 1930, diferentes grupos defendiam a "bandeira" de Getúlio Vargas visando mudanças no cenário político que compreendiam os princípios nacionalistas. Esse projeto político também recebeu apoio do Ministério da Educação e de outras áreas que cooperaram na propagação de seus ideais, uma delas, a imprensa.

Segundo Vieira (2012), o civismo foi inserido no espaço escolar cooperando para a formação de cidadãos que desenvolvessem sentimentos patrióticos.

\footnotetext{
${ }^{1}$ O Despertar foi uma produção do órgão de ensino de Caxias do Sul que teve como público-alvo os professores, alunos das escolas rurais e suas famílias, sua circulação iniciou em 1947, era distribuído gratuitamente e a sua tiragem compreendia uma média de 1200 exemplares mensais.

${ }^{2}$ A produção das matérias do Despertar ficava a critério de profissionais vinculados a Diretoria de Instrução Pública de Caxias do Sul, sob a coordenação da professora Ester Troian Benvenutti.
} 
Nesta trajetória, os livros didáticos assumiram diferentes formas discursivas: livros de leitura, cartas Constitucionais adaptadas e comentadas, contos, poesias, narrativas biográficas enfim, um amplo leque de gêneros narrativos que ora privilegiaram temas patrióticos, ora enfatizaram abordagens sobre leis pertinentes à organização política dos países. (VIEIRA, 2012, p. 327).

Nesse contexto, é possível inferir que no cenário caxiense há uma introdução bastante semelhante dos pensamentos de civismo, ou seja, a escola é usada como um meio para a inserção dessas ideias; e uma forma discursiva, com características das produções de imprensa, o jornal Despertar, é empregado para a propagação desses ideais de civismo. Evidências de que o governo municipal contemplava, em suas ações, as propostas desenvolvidas durante o nacionalismo no Brasil.

Em diferentes colunas do Despertar, há a utilização de símbolos da pátria em mensagens às famílias, em notícias sobre os feitos da administração, e nas atividades propostas para as crianças, tais como o excerto:

Marcha à bandeira. Esta é a minha bandeira! É cheia de encantos mil! Tremula, toda faceira, no coração do Brasil! Não há quem não a conheça, seja do norte ou do sul. É de ouro! E não se esqueça: Tem branco, verde e azil!... Gosto de minha bandeira! Sei amá-la com fervor! Em dias de brincadeira, Enfeito-a toda de flor. (DESPERTAR, 1954c, p. 3).

Corrobora com essa ideia o conteúdo do Programma Official para o Ensino nas Escolas Rurais do ano de 1936, editado pela Diretoria de Instrução Pública de Caxias do Sul, documento que serviu como um manual de orientação aos professores locais. Apesar de sua edição ter antecedido o recorte desta pesquisa, os temas tratados no documento coincidiam com os assuntos abordados por intermédio da escola e, que foram evidenciados no Despertar.

Nesse programa há prescrições que orientam os professores quanto ao conteúdo a ser ministrado na escola: “ $3^{\circ}$ ANNO - HISTORIA - [...] a mestra deverá ter a preocupação de pôr em relevo as personalidades predominantes dos fatos explicados e a sua actuação na formação da nossa nacionalidade [...] para o despertar do sentimento patriotico nas crianças[...]" (CAXIAS DO SUL, 1936a, p. 4-6-8-9-11). Ainda há a orientação para que os professores atuem no sentido da promoção do sentimento patriótico entre as crianças: [...] $4^{\circ}$ ANNO OBSERVAÇÃO: A professora procurara em todas as aulas levantar o sentimento cívico, fazendo vêr ao alumno que a nação mais forte será aquella que tiver filhos fortes [...]" (CAXIAS DO SUL, 1936a, p. 4-6-8-9-11). 
Há semelhança entre o conhecimento proposto pelo programa e o conteúdo publicado no periódico, o que pode ser visto no excerto do periódico que segue:

FIGURA 1 - Recorte do Despertar.

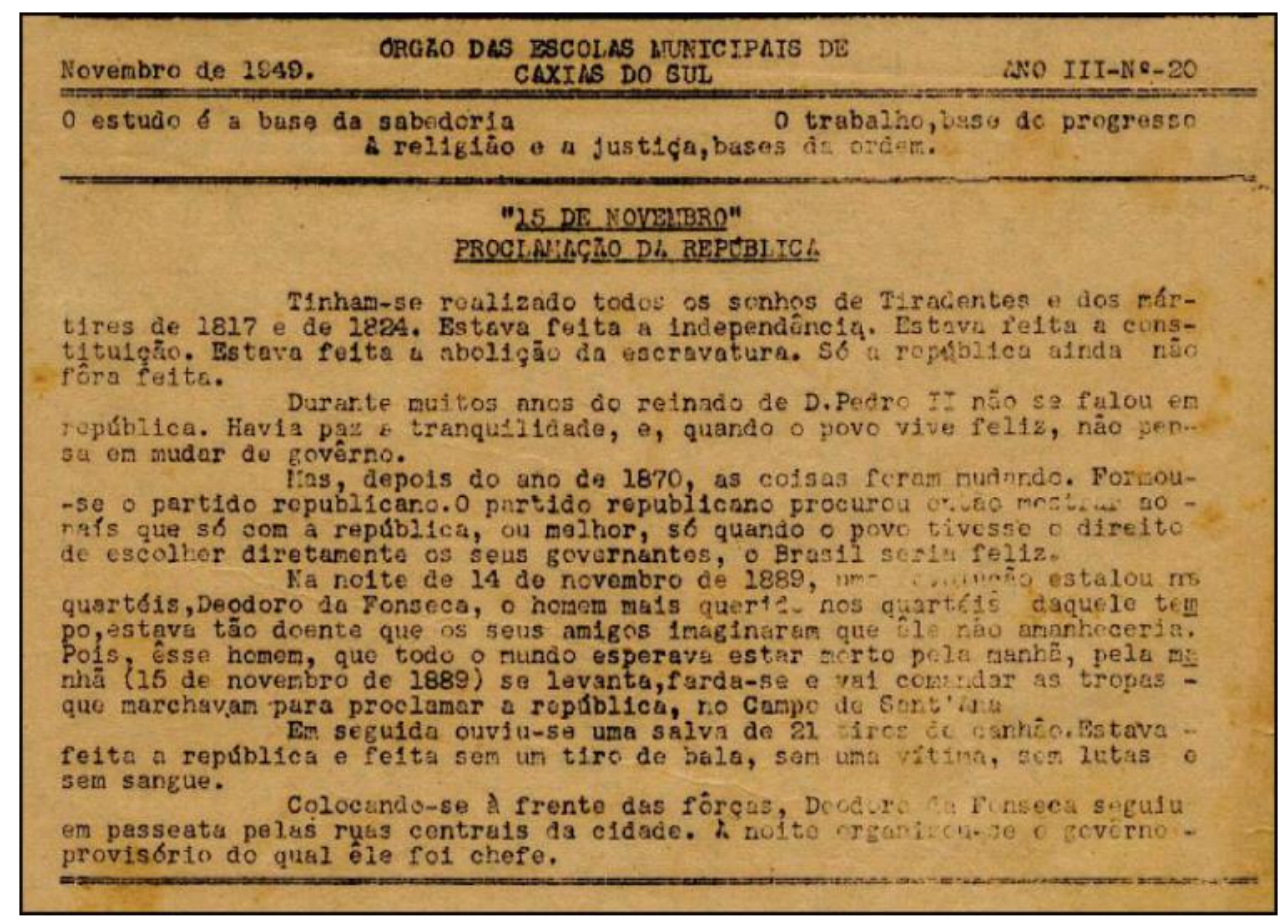

Fonte: Despertar, 1949b.

Sousa (2015) aborda sobre o uso de outra forma discursiva que colaborava para a disseminação de pensamentos alinhados ao de civismo, os manuais de educação moral e cívica. De acordo com o pesquisador, durante a ditadura militar, eles serviram para incutir valores e para propagar a ideologia defendida pelo regime político, reforçando ideais de hierarquia, autoridade, ordem e tradição, questões associadas aos valores patrióticos.

Os símbolos pátrios, as citações sobre os "personagens" importantes da história do Brasil, a aprovação a certos comportamentos, as mensagens que tratavam sobre obediência, a indicação de atitudes que expressariam o sentimento de amor ao Brasil, esses e outros assuntos associados ao civismo, estiverem presentes nas páginas do Despertar. O jornal não foi um manual, mas ocupou um papel equivalente na propagação desses ideais, que no recorte de tempo sinalizavam para o nacionalismo no Brasil. E, a escola foi a mediadora, inspirando na construção de novos e diferentes sentidos que motivavam as práticas desenvolvidas pelas comunidades que viviam no seu entorno.

As reflexões anteriores colocam o Despertar tanto como um material de uso pedagógico, como um aparato estratégico da administração pública para uma aproximação à comunidade rural. Artificio usado com a intenção de orientar para a tomada de determinados 
comportamentos acordados com os de civismo. A função do periódico, pelo menos a que era desejada pelos gestores do poder público municipal, pode ser evidenciada no recorte a seguir:

FIGURA 2 - Recorte do Despertar.

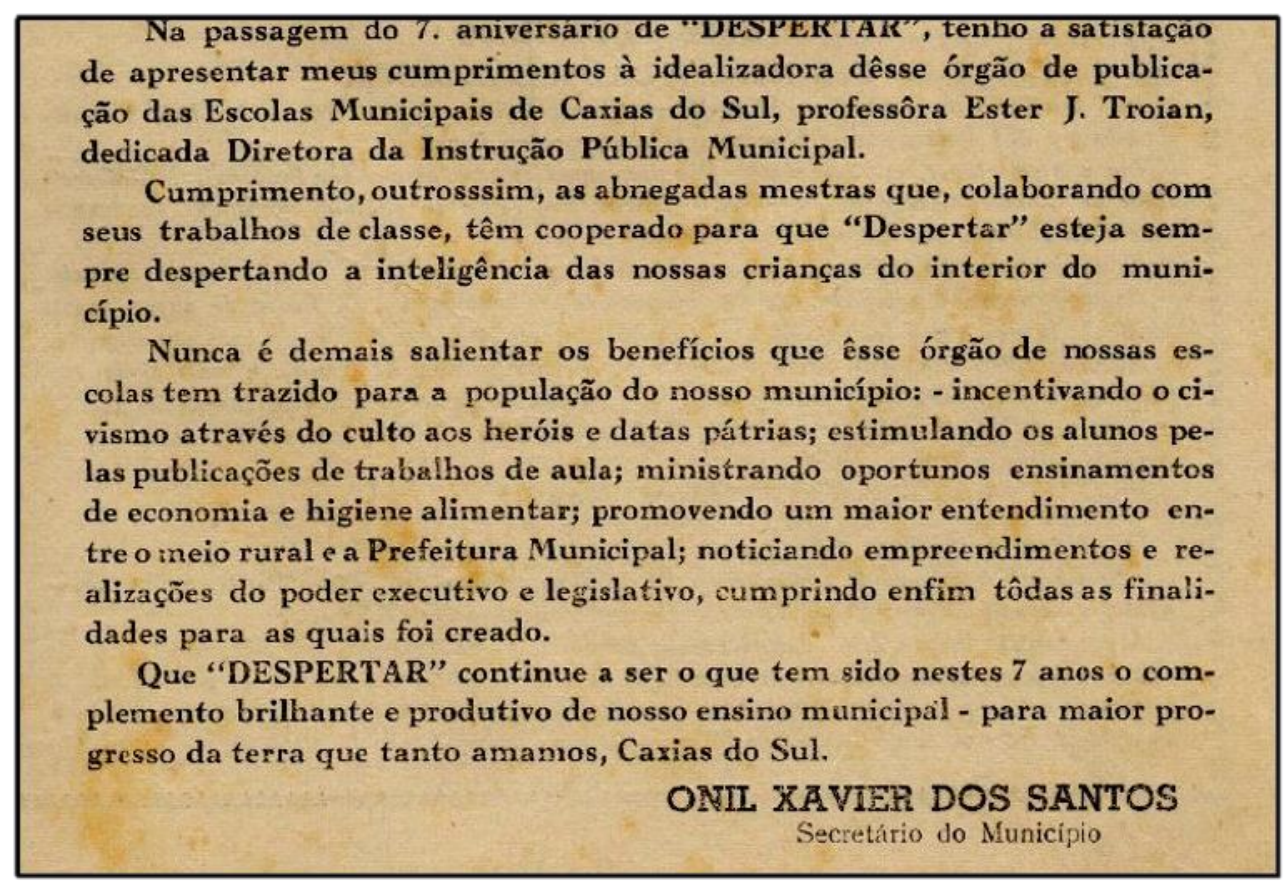

Fonte: Despertar, 1954c.

Para Almeida (2005), a educação nas escolas rurais devia ser capaz de instrumentalizar os sujeitos, formando-os e moldando-os para estarem adaptados ao espaço de origem, mas preparados para o meio urbano. "E a escolarização é quem vai preparar e instrumentalizar o homem rural para enfrentar as mudanças sociais e econômicas, só assim poderá estar apto a participar e compreender as ideias de progresso e modernidade que emergem no país" (ALMEIDA, 2005, p. 287).

Nesse sentido, em matérias do Despertar observou-se o civismo associado a outros temas, tais como, a civilidade e o trabalho. Esse último tema, usado frequentemente como referência ao progresso do município. O trabalho, no periódico, é utilizado com destaque. Essa constatação é feita, particularmente, porque a palavra aparece no seu slogan: "O estudo é a base da sabedoria. O trabalho, base do progresso. A religião e a justiça, bases da ordem”. Considerou-se que o slogan expressava a essência do periódico, na visão de seus produtores. Dessa forma, a intenção de seus produtores poderia ser a de transportar os seus leitores a lugares diferentes dos até então reconhecidos por eles, em suas experiências no espaço rural. E, com isso, cooperaria para atribuir sentido a determinadas práticas propostas pela administração municipal. 
Cabe aqui um adendo para esclarecer quanto ao interesse do poder público municipal em disseminar o civismo nas localidades rurais de Caxias do Sul, que pode ser justificado pelo fato de que um número significativo de imigrantes italianos, ou descendentes de italianos, constituíram morada nessas localidades. Tendo em vista que as ações nacionalistas também tinham como propósito impedir o fortalecimento das ideologias dos países de origem dos imigrantes, as ações da administração municipal caxiense podem apontar para esse sentido. De acordo com Gertz (2005), havia a preocupação das autoridades nas regiões de colonização desses imigrantes, de modo especial, no Rio Grande do Sul, por isso ocorreu uma atuação nacionalizadora em escolas, objetivando, especialmente, coibir o uso da língua estrangeira.

Retomando a questão do trabalho e, conectando o tema às ações nacionalistas aplicadas aos imigrantes italianos, podemos considerar que as ideias como a expressa no trecho " $\mathrm{O}$ trabalho, base do progresso" estavam entranhadas em tais comunidades, porque integravam os valores compartilhados por aquelas pessoas, e o desejo delas ao se estabelecerem nos espaços rurais. Ou seja, o de fortalecerem a identidade dessas comunidades em torno do trabalho com a agricultura. Por isso, abordar o civismo com referência ao trabalho, pode ter facilitado a introdução e aceitação dos comportamentos e práticas defendidas pelo poder público municipal. Fico (1997) explica que o trabalho era um elemento que estava associado ao civismo quando se distinguia as características da identidade do "cidadão brasileiro", durante o Estado Novo:

\footnotetext{
Pode-se dizer que, durante o Estado Novo, a assim chamada "identidade brasileira" seria amplamente redefinida - pelo menos do ponto de vista governamental. Muitos dos elementos que posteriormente, durante a ditadura militar pós-64, seriam utilizados pela propaganda política foram estabelecidos nessa época: a valorização da mistura racial, a crença no caráter benevolente do povo, o enaltecimento do trabalho, uma certa idéia de nação - baseada nos princípios de coesão e da cooperação. Pode-se dizer, então, que essas são matrizes ideológicas do Estado Novo que seriam retrabalhadas pela ditadura militar. (FICO, 1997, p. 34).
}

A valorização ao homem que realizava o trabalho na agricultura foi expressa em várias colunas do Despertar. Além disso, foi possível verificar que havia o interesse em incentivar novas práticas na área rural, consideradas modernas para a época, em trechos com orientações para o cultivo, e notícias sobre a aquisição e empréstimo de máquinas e ferramentais para os agricultores, e a introdução de Clubes Agrícolas. Essas são evidências das ações desenvolvidas para habilitar as pessoas, especialmente, as mais jovens, para o trabalho na área rural, o que colaborava para a continuidade da agricultura familiar e, consequentemente, do desenvolvimento da economia agrícola no município. Esses temas foram abordados no período 
do Nacionalismo, pelo Decreto de Lei n 9613, de 20 de agosto de 1946, que definia a organização de ensino voltada para a qualificação dos jovens para o trabalho nas áreas rurais (BRASÍLIA, 1946b, s/p).

Na matéria a seguir, publicada no noticiário do Despertar é possível verificar o incentivo da administração de Caxias do Sul para a instalação dos Clubes Agrícolas:

No decorrer do ano em curso serão criados, mais cinco Clubes Agrícolas anexos às escolas Municipais. Na Escola "GUIA LOPES" em S. Marcos, já estão concluídos os trabalhos de entendimento sobre a doação do terreno necessário para a instalação de um clube Agrícola que funcionará dentro em breve. As professoras regentes interessadas na fundação dessa útil instituição, devem procurar mais informações na diretoria da Instrução. (DESPERTAR, 1951b, p. 8).

Outra questão evidenciada na leitura do Despertar é a que aborda sobre um determinado sentimento de gratidão dos imigrantes em relação a pátria brasileira. Em diferentes trechos é possível perceber mensagens que relacionam essa gratidão aos comportamentos esperados e preconcebidos como sendo um modelo de cidadão brasileiro. Uma estratégia que pode ter sido usada para a inserção de ideias sobre o civismo e, particularmente, para influenciar essas comunidades para o aprendizado da língua portuguesa. Em excerto como o que segue é possível observar as publicações do Despertar: "Para sermos bons brasileiros devemos: prezar nossa amada Pátria, defender e cultivar o passado histórico e falar somente nossa língua" (DESPERTAR, 1947a, p. 7). A defesa do uso da língua portuguesa aparece no artigo 76, da legislação do município, que preconiza a utilização da língua nacional de forma obrigatória, em estabelecimentos de ensino: “A legislação do ensino municipal adotará sempre os seguintes princípios: I - o ensino primário é obrigatório e só será dado em língua nacional [...]” (CAXIAS DO SUL, 1948a, p. 19).

Luchese (2014) faz reflexões quanto às imposições nacionalistas à comunidade italiana, especialmente a que se referia ao uso da língua materna, a partir de 1942, o que impunha dificuldades, particularmente à população mais idosa.

Em depoimento a historiadores locais, a professora Ester Troian Benvenutti relembra um dos episódios de demonstração de civismo no âmbito da escola rural:

E esta questão da nacionalização, naquela época, eles ficaram atemorizados, que na, na parte de origem alemã, principalmente, quando eu ia visitar as escolas lá de São Sebastião do Caí, as crianças, [...] de pé e gritavam: "Viva el Brasil"! "Viva el Brasil”! Tinha que mandar parar. Elas tinham até receio. [...] E os nossos colonos, [...] cantavam muito as canções que foram 
traduzidas, não vamos dizer literalmente do italiano, mas foram adaptadas por D. José Baréa [...] cantavam, "Não há terra mais bonita e encantadora do que a terra que se curva sobre mares. / Estendendo lindos leques em seus palmares. Minha terra sempre em flor". [...] Mas, o espírito de brasilidade dos nossos imigrantes, naquela época, era tão grande [...] os velhos, e os novos, os pais ensinavam amar a sua segunda Pátria, como a Pátria deles de origem [...]. (BENVENUTTI, 1983, p. 9).

As lembranças da professora Ester Troian Benvenutti nos fazem crer que não havia objeção, por parte dos colonos italianos, no aprendizado da língua portuguesa. Houve o interesse na adoção da língua, possivelmente porque essas comunidades ansiavam por espaços para a escolarização das crianças. Outro fato interessante é a preservação de certas heranças culturais, que sobrevivem ainda hoje, especialmente nas áreas rurais de Caxias do Sul. Evidenciou-se na entrevista concedida pela professora Ester que certas práticas não haviam sido abolidas ou proibidas dentro das comunidades rurais, entre elas, os filós ${ }^{3}$, inclusive com a participação das docentes (BENVENUTTI, 1983, p. 9).

Apesar de manterem presentes determinadas tradições de seu país de origem, observase que há uma certa receptividade, das pessoas que viviam na área rural caxiense às manifestações de valorização e reconhecimento da "segunda" pátria, a brasileira. Entre as notícias publicadas no Despertar o tema civismo também aparece intrinsecamente na realização de confraternizações e eventos, como os descritos a seguir: "Num sadio ambiente de confraternização cívica, civis e militares comungaram no dia de ontem dos mesmos propósitos e aspirações [...]" (DESPERTAR, 1953a, p. 8). "Dando início à solenidade, foi cantado o Hino Nacional e a professôra regente srta. Alda Isotton saudou o Sr. Prefeito Municipal [...]" (DESPERTAR, 1954c , p. 12). E, ainda em excertos como: “A Diretoria de Instrução Pública avisa aos professores [...] que as comemorações internas da Semana da Pátria [...] devem obedecer à mesma orientação [...] professores empreguem o máximo dos seus esforços para que [...] se revistam do maior brilhantismo [...] (DESPERTAR, 1954c, p. 12) .

Das matérias do Despertar emergiram relevantes evidências sobre a história da educação na cidade de Caxias do Sul, o conteúdo de suas colunas permitiu compreender algumas das estratégias utilizadas pelo órgão de ensino para a introdução de práticas que despertariam o sentimento cívico nas pessoas que viviam nas áreas rurais. Do mesmo modo, possibilitou a reflexão sobre como eram construídas as representações sobre o civismo, a fim de que aquelas comunidades conferissem significado sobre elas. $\mathrm{O}$ civismo que emergiu nas

\footnotetext{
${ }^{3}$ Os filós são um dos aspectos da vida social das comunidades italianas, consiste em encontros de pessoas da comunidade, nos quais, eram difundidas notícias; homens, mulheres e crianças se reuniam para conversar, rezar, dançar, comer e beber. (GOMES, 2008, n/p).
} 
páginas do periódico, mostrava o empenho da administração municipal para propagar ideias de obediência, de trabalho e do progresso associado a comportamentos enquadrados como atitudes patrióticas, pois entendiam que esses valores eram importantes para o "progresso" do município.

\section{CONSIDERAÇÕES FINAIS}

O Despertar desempenhou um papel relevante dando o aporte de conteúdo aos docentes da área rural, e cooperando na escolarização das crianças e em uma formação mais técnica para as comunidades rurais. Com isso, colaborava para a constituição de cidadãos adequados aos parâmetros desejados pelas políticas da época, especialmente as que se relacionavam ao Nacionalismo. Ainda foi um aparato usado a favor dos interesses do poder público municipal, ao passo que propagava as representações necessárias para a apropriação de determinadas práticas que visavam o desenvolvimento de um sentimento patriótico.

O Despertar tratou de uma infinidade de temas que despertavam o interesse das pessoas que viviam na área rural de Caxias do Sul. Por isso, cumpriu a função para o qual foi criado, e cooperou para que a administração municipal chegasse próxima aos seus objetivos. Disseminou orientações que visavam transformar as práticas dos habitantes das áreas rurais, direcionando-os a adequação de comportamentos que não estavam acordados aos padrões da época; cumpriu um papel importante para a formação de crianças e jovens, ao passo que oferecia conhecimentos aos professores das escolas rurais, habilitando-os para uma atuação mais específica e técnica. É preciso destacar que a abordagem sobre o tema civismo que permeou diferentes colunas do periódico, permite identificar uma série de outros assuntos relacionados ao civismo. Entender como as estratégias do poder público eram pensadas, no sentido de cooperar para a formação de um cidadão que internalizasse o sentimento de amor à pátria brasileira, e que por intermédio de diferentes práticas, exteriorizasse as orientações repassadas por meio do periódico.

Desse modo, cooperou para a formação de sujeitos de acordo com os preceitos de civismo que permeavam o nacionalismo no Brasil. Buscou fortalecer uma identidade de cidadão brasileira no íntimo de comunidades que ainda partilhavam a herança cultural de suas pátrias de origem. Estabeleceu um espaço que inspirava confiança - o Despertar, que tratava de assuntos que eram essenciais para a manutenção da vida na área rural. O periódico foi um significativo meio utilizado para a propagação de representações sobre o civismo e, 
consequente engajamento das pessoas que viviam nas áreas rurais para os comportamentos admitidos como de "verdadeiros cidadãos brasileiros"; o que favorecia a inserção de novas práticas ou a transformação das práticas já exercitadas. O Despertar se constituiu em um guia para as práticas nas áreas rurais, que abordou de uma forma simples e descomplicada diferentes temas, introduzindo orientações que propiciaram a adoção de práticas, incluindo as de civismo.

Ressalta-se que essa análise permite visibilidade quanto à difusão das ideias de civismo por meio de aparatos de imprensa em regiões rurais do nosso país, refletindo-se na amplitude de sua utilização e em uma abrangência que transcende o eixo sudeste do Brasil, adentrando em outras regiões, inclusive em cidades do interior. Salienta-se, ainda, que esse texto poderá contribuir com reflexões para outros estudos que empregam como fonte ou objetos de pesquisa os periódicos, e que poderá cooperar para a construção de diferentes ou outras percepções e compreensões sobre os usos dados a esses aparatos e estratégias investidas pelas instâncias de poder, em recorte temporal semelhante, e a forma como refletiram na educação promovida pelas escolas no país.

\section{REFERÊNCIAS}

ALMEIDA, D. B. A Educação rural como processo civilizador. In: STEPHANOU, M; BASTOS, M,H,C. (Org). Histórias e memórias da educação no Brasil. Vol I. Século XX. Petrópolis: Vozes, 2005.

AGUIAR JUNIOR, Arimatéa Freitas. Construção do Civismo e da Ordem: as festas oficiais comemoradas em Teresina no período de 1935 a 1945. In: ENCONTRO REGIONAL DE HISTÓRIA ORAL, 2013, Campinas. Anais eletrônicos [...] Campinas: ABHO-Regional Sudeste e CMU-Unicamp, 2013. Disponível em: https://www.sudeste2013.historiaoral.org.br/resources/anais/4/1374340204_ARQUIVO_Jose deArimateaFreitas AguiarJunior.pdf. Acesso em: 15 abr. 2019.

CARNEIRO, M. L. T. Livros proibidos, ideias malditas. O DEOPS e as minorias silenciadas. 2. ed. São Paulo: Ateliê Editorial, 2002.

CHARTIER, Roger. A história cultural. Entre práticas e representações. Tradução de Maria Manoela Galhardo. Lisboa: Difusão, 1988.

CHARTIER, Roger. O mundo como representação. Estudos avançados, São Paulo, v. 5, n. 11, abr. 1991.

SOUZA, José Edimar. Revista Eletrônica História em Reflexão FGV - Fundação Getúlio Vargas. Verbete: Euclides Triches. Disponível em:

http://www.fgv.br/cpdoc/acervo/dicionarios/verbete-biografico/triches-euclides. Acesso em: 11 jan. 2019. 
FICO, Carlos. Reinventando o Otimismo: ditadura, propaganda e imaginário social no Brasil. Rio de Janeiro: Fundação Getúlio Vargas, 1997.

LUCHESE, Terciane Ângela. Itinerários das escolas italianas em terras brasileiras: uma história contada pelos materiais didáticos (1875-1945). In: ANPEDSUL, 10, Florianópolis, 2014. Anais [...]. Florianópolis: [s. n], 2014. Disponível em:

http://xanpedsul.faed.udesc.br/arq_pdf/219-0.pdf. Acesso em: 27 jun. 2019.

PESAVENTO, Sandra Jatahy. Cultura e Representações, uma trajetória. Anos 90, Porto Alegre, v. 13, n. 23/24, p.45-58, jan./dez. 2006. Disponível em:

https://seer.ufrgs.br/anos90/article/view/6395/3837. Acesso em: 03 mar. 2019.

SOUSA, Reginaldo Cerqueira. Uma higiene moral e do corpo: educação moral e cívica, as atividades físicas, esportivas e de lazer durante a ditadura militar. Revista Cordis, São Paulo, n. 14, p. 18-37, jan./jun. 2015. Disponível em:

https://revistas.pucsp.br/index.php/cordis/article/view/26135\&gt. Acesso em: 22 mar. 2019.

TAMBARA, Elomar Antonio Callegado; ARRIADA, Eduardo. Civismo e educação na primeira república - João Simões Lopes Neto. História da Educação, Pelotas, v.13, n. 27 p. 279-292, jan./abr. 2009. Disponível em: https://seer.ufrgs.br/asphe/article/view/29036. Acesso em: 22 mar. 2019.

VIEIRA, Cleber Santos. Civismo, República e manuais escolares. Revista Brasileira de História, São Paulo, v. 32, n. 63, p. 325-340, 2012

\section{FONTES DOCUMENTAIS}

BENVENUTTI, Esther Troian. Entrevista concedida a Juventino Dal Bó e Liliana Alberto Herichs. Caxias do Sul, 1983, fg 004-005.

BRASÍLIA, Câmara dos deputados. Decreto de Lei no 9613, de 20 de agosto de 1946b. Disponível em: https://www2.camara.leg.br/legin/fed/declei/1940-1949/decreto-lei-9613-20agosto-1946-453681-publicacaooriginal-1-pe.html. Acesso em: 3 jan.

CAXIAS DO SUL. Programma Official para o Ensino nas Escolas Ruraes do Município de Caxias, 24 de abril de 1936a.

CAXIAS DO SUL. Lei Orgânica do Município - 1948. 27 de mar. de 1948a.

Disponível em: http://arquivomunicipal.caxias.rs.gov.br/index.php/lei-organica-do-municipio7. Acesso em: 3 mar. 2019.

DESPERTAR. Caxias do Sul, novembro de 1947a. Disponível em:

http://arquivomunicipal.caxias.rs.gov.br/index.php/jornal-despertar-2. Acesso em: 03 jan. 2018.

DESPERTAR. Caxias do Sul, julho e agosto de 1948c. Disponível em:

http://arquivomunicipal.caxias.rs.gov.br/index.php/jornal-despertar-2. Acesso em: 03 jan. 2018. 
DESPERTAR. Caxias do Sul, julho e agosto de 1948a. Disponível em:

http://arquivomunicipal.caxias.rs.gov.br/index.php/jornal-despertar-2. Acesso em: 03 jan. 2018.

DESPERTAR. Caxias do Sul, novembro de 1949b. Disponível em:

http://arquivomunicipal.caxias.rs.gov.br/index.php/jornal-despertar-4. Acesso em: 03 jan. 2018.

DESPERTAR. Caxias do Sul, setembro de 1951a. Disponível em:

http://arquivomunicipal.caxias.rs.gov.br/index.php/jornal-despertar-6. Acesso em: 03 jan. 2018.

DESPERTAR. Caxias do Sul, março de 1951B. Disponível em:

http://arquivomunicipal.caxias.rs.gov.br/index.php/jornal-despertar-6. Acesso em: 03 jan. 2018.

DESPERTAR. Caxias do Sul, julho de 1952a. Disponível em:

http://arquivomunicipal.caxias.rs.gov.br/index.php/jornal-despertar-7. Acesso em:

03 jan. 2018.

DESPERTAR. Caxias do Sul, outubro de 1953a. Disponível em:

http://arquivomunicipal.caxias.rs.gov.br/index.php/jornal-despertar-8. Acesso em: 03 jan. 2018.

DESPERTAR. Caxias do Sul, setembro de 1954c. Disponível em:

http://arquivomunicipal.caxias.rs.gov.br/index.php/jornal-despertar-9. Acesso em: 03 jan. 2018.

Recebido em: 14 de dezembro de 2020

Aceito em: 22 de dezembro de 2020 